\title{
Franz Kafka no cinema
}

animado: uma análise da

adaptação japonesa e do

conto Um médico rural

\section{Luísa Rizzatti}

Mestranda em Teoria Literária pela Universidade Federal do Rio Grande do Sul (UFRGS), com projeto sobre o escritor Franz Kafka. Graduada em Jornalismo pela UFRGS.

E-mail: luisarizzatti@hotmail.com

\section{Cida Golin}

Doutora em Letras. Jornalista e professora dos cursos de Jornalismo e Museologia da Universidade Federal do Rio Grande do Sul e professora do Programa de Pós-Graduação em Comunicação da UFRGS.

E-mail: golin.costa@ufrgs.br
Resumo: Por meio do diálogo comparado entre audiovisual e literatura, este artigo analisa o conto Um médico rural, de Franz Kafka, e a sua adaptação para o cinema a partir da animação homônima criada pelo japonês Koji Yamamura. O objetivo central é compreender e investigar como as características narrativas e a atmosfera criada no fantástico de Kafka são trabalhadas na animação. Através da análise fílmica, verificamos que os principais recursos utilizados foram as deformações gráficas no desenho das personagens, o exagero nos gestos, a ênfase no modo de se movimentar das figuras, as abruptas mudanças de acelerações e uma colorização com tons frios e amarelados. A ambientação sonora perturbadora do violino e do piano e as interpretações vocais dos dubladores japoneses foram cruciais para recriar o fantástico kafkiano no audiovisual animado sob um novo olhar.

Palavras-chave: Adaptação; Animação; Franz Kafka; Um Médico Rural; Koji Yamamura.

Franz Kafka in the animated film: an analysis of the Japanese adaptation and of the short story $A$ country doctor

Abstract: This article analyzes $A$ country doctor, a short story written by Franz Kafka, and its adaptation to the cinema, the homonymous animation created by the Japanese artist Koji Yamamura. The objective is to investigate how the narrative and the atmosphere in the fantastic of Kafka are applied to the animation through the comparative dialogue between audiovisual and literature. It was verified that the main features used were the graphic deformations in the characters' design, the exaggeration of gestures, the emphasis on the peculiar motion of figures, the abrupt accelerations and the colorization that privileged cold or yellowish tones. The disturbing sound environment, marked by the violin, the piano and the vocal interpretations of the Japanese voice actors were also configured as crucial elements to re-create the Kafkaesque fantastic.

Keywords: Adaptation; Animation; Franz Kafka; A Country Doctor; Koji Yamamura. 


\section{Considerações iniciais}

Nascido no ano de 1883, Franz Kafka consagrou-se como um dos autores mais influentes do século XX. Oriundo de uma minoria, sendo judeu e tcheco, enfrentou os desafios de criar uma literatura revolucionária a partir do alemão, uma língua tida como maior. Independentemente do gênero literário, os seus textos possuem algumas características bastante semelhantes entre si: são unidos pela problemática do fracasso, do desconhecimento e da impotência experimentados pelos protagonistas.

Este artigo busca compreender e investigar como as características narrativas e a atmosfera criada no fantástico de Kafka são recriadas em outra mídia, no caso, o audiovisual de animação. Trabalharemos com o conto Um médico rural e com a animação homônima realizada pelo artista japonês Koji Yamamura. Trata-se de um curta-metragem de 21 minutos, lançado em 2007 e agraciado em importantes premiações, como o Festival Internacional de Animação Ottawa e o Mainichi Film Awards, ambos em 2007.

Yamamura nasceu em Nagoya, no Japão, em 4 de junho de 1964. Em 1993, fundou a Yamamura Animation, tendo como única sócia a sua esposa Sanae, uma artista plástica especializada em pintura abstrata. Indo em uma direção oposta a da estética atrelada aos japoneses, fortemente caracterizada pelo anime e pelo mangá, o artista voltou-se a referências mais distantes de seu país de origem. Como criador de histórias, busca inspiração em pintores, escritores e inventores europeus, enquanto suas animações são influenciadas pelos legados da National Film Board of Canada (NFB). Yamamura não é adepto de técnicas 3D: desenha diretamente no papel, tendo à sua disposição uma infinidade de lápis de cor; depois, escaneia o trabalho artístico e organiza as camadas usando o software de animação japonesa.

Para realizarmos o diálogo entre cinema e literatura, começaremos com uma breve contextualização do universo kafkiano. Em seguida, entraremos no debate acerca da adaptação a partir de Linda Hutcheon (2013) e Roland Barthes (2004). Por fim, por meio da análise fílmica (VANOYE; GOLIOT-LÉTÉ, 2008) ancorada em elementos da estética das animações (FURNISS, 2007) e categorias do universo literário de Kafka, faremos a leitura da animação Um médico rural em paralelo ao conto que lhe dá origem.

\section{O universo kafkiano}

Dentro de uma lógica opressiva, as personagens kafkianas carregam um enorme fardo, pois "o que sustentam não é o mundo: é o quotidiano, tão pesado como o globo terrestre" (BENJAMIN, 1994: 25). São personagens que não têm salvação, vivem cada dia igual, sempre perdidas em uma falta de esperança. Estão fadadas ao insucesso e, de antemão, são sempre culpadas. Na obra de Kafka, não há espaço para a redenção.

Assim, as personagens não possuem liberdade nem para tentar mudar o rumo da sua história, de forma que até se parecem com marionetes, tendo a sua vida manipulada e vivida por outros. Existe uma espera muito marcante por algo que $o$ sujeito não sabe muito bem o que é, de modo que a lógica do seu agir e pensar se configura em círculos. A partir disso, o filósofo alemão Günther Anders (2007: 55) identifica que esse processo desencadeia uma "paralisação do tempo", que, por sua vez, produz imagens paralisadas. Nesse ponto, a ideia de Anders dialoga com o que Theodor Adorno (1998) defendeu sobre a escrita de Kafka se parecer com a pintura expressionista, uma vez que "[...] a prosa de Kafka está muito mais próxima da 'arte plástica', porque, para ele e para as pessoas do seu mundo, a vida é tão enroscada que não anda; e também porque essa imobilidade só pode se estabelecer como imagem" (ANDERS, 2007: 74). 
Ademais, o sujeito acaba sendo esvaziado de sua singularidade, colocado em posições reificadas, de modo que o herói geralmente é um homem-profissão (ANDERS, 2007). Nesses casos, a personagem desaparece totalmente para apenas assumir uma função. Portanto, a profissão surge como uma forma exclusiva de existência do homem. O protagonista do nosso objeto, por exemplo, nem nome tem, é apenas designado como médico rural.

Em relação à classificação da obra, pensamos que Kafka pode sim pertencer ao gênero fantástico, mas de um modo bem peculiar. Sua escrita possui elementos que o aproximam do gênero, assim como cria mecanismos que provocam um distanciamento significativo. Em Kafka, existe uma inversão narrativa em relação à estrutura do fantástico tradicional (TODOROV, 1975): ao invés de existir um início com acontecimentos tidos como convencionais e, aos poucos, atingir uma situação absurda, parte-se do sobrenatural, isto é, de uma situação completamente estranha, para finalizar o texto com uma aparência natural, como se não houvesse algo inusitado desde o começo.

Dentro desse processo, há uma mudança do elemento que aparece ao longo das narrativas do escritor tcheco: em vez da hesitação que prepara o leitor para o clímax do insano, Kafka desenvolve um processo de adaptação da personagem para que ela consiga passar do fato estranho ao ordinário (TODOROV, 1975). Ao inverter as estruturas narrativas, o escritor produz um deslocamento daquilo que é comumente considerado como insanidade e normalidade, numa operação que Anders chamou de "deformação como método" (ANDERS, 2007: 16). Como consequência, surge outra característica crucial, que seria a "trivialidade do grotesco" (ANDERS, 2007: 20). Suas personagens reagem naturalmente às situações tidas como inquietantes, de modo que os elementos grotescos são assimilados como pertencentes à ordem do normal.

Outro viés importante de ser observado é o caráter gestual e visual da obra de Kafka (BENJAMIN, 1994). Benjamin identifica que o mundo de Kafka é como se fosse um teatro, em que o homem está em cena naturalmente. Nessa mesma perspectiva, o autor ainda aponta o gesto que aparece mais frequentemente nas histórias do tcheco: o movimento do herói de inclinar profundamente a cabeça sobre o peito, seja por cansaço, seja por servilismo (BENJAMIN, 1994). Essa espécie de acontecer cênico, portanto, é um elemento importante e marcadamente repetido nos textos kafkianos.

No que tange ao seu estilo de escrita, a linguagem presente nos textos de Kafka não é rebuscada; é, antes de tudo, clara sem ser pobre. Não são palavras mirabolantes, nem revoluções na ordem da frase que deixam as suas narrativas complexas. Dessa forma, confirmamos, em Kafka, uma escrita calculista, minuciosa, que busca uma precisão eficaz. Anders aponta, também, uma espécie de "linguagem de protocolo" (ANDERS, 2007: 91), sóbria, marcada pela exatidão de petições e comunicados oficiais. Se o seu mundo é o da burocracia, sua linguagem o alimenta.

Para encerrar o âmbito formal, lembramos que, tradicionalmente, a voz narrativa revela algumas informações importantes sobre a trama, sobretudo quando está na terceira pessoa e carrega consigo um poder de onisciência, trazendo alguns pensamentos que até podem ser os do próprio escritor. O diferente, entretanto, é que Kafka obscurece até a visão que teria a chance de ser a mais límpida de todas através da criação de um narrador insciente (CARONE, 2009), de modo que a condição do nada saber toma conta até do narrador, figura que poderia ser fonte de elucidação dos acontecimentos. Esse é o momento em que o aspecto temático entra em comunhão com o plano estético.

Depois dessa breve contextualização das características do escritor, começaremos a explorar noções de adaptação para, posteriormente, perceber de que maneira a literatura de Kafka pode ser trabalhada em outra mídia. 


\section{Adaptação como palimpsesto}

Linda Hutcheon (2013) defende que, em qualquer cultura, o ser humano sempre criou adaptações ao contar e recontar histórias tanto individuais como de outras pessoas. Diante disso, a autora canadense defende que há dois sentidos para o termo. O primeiro refere-se à adaptação como um produto que pode experimentar mudanças de mídia, de gênero, de foco, ou de ontologia (do real para o ficcional, no caso). Podemos pensar em poemas, romances, peças de teatro, óperas, quadros, músicas, danças, parques temáticos, representações históricas, experimentos de realidade virtual, videogames, quadrinhos, sites virtuais, por exemplo. Esse produto, sendo uma adaptação, obrigatoriamente se vincula a uma obra anterior, por mais que seja algo novo.

Isso é o que a autora chama de adaptação como adaptação (HUTCHEON, 2013), considerando que essas são "obras inerentemente 'palimpsestuosas', [...] assombradas a todo instante pelos textos adaptados" (HUTCHEON, 2013: 27). Devemos levar em conta que a adaptação é uma maneira de repetir algo (trazer elementos da obra "original"), mas também de propor variações, uma vez que quaisquer mudanças (sejam de mídia, sejam de gênero, por exemplo) exigem reformatações. Assim, as adaptações são objetos estéticos por si só, mas não podemos esquecer ou anular a relação que mantêm com uma obra de origem, pois são produções caracterizadas pela sua multiplicidade de camadas.

Já o segundo sentido para o termo busca pensar a adaptação como processo, dentro do qual está inserida a figura do adaptador, pessoa responsável por construir "tanto uma (re)interpretação quanto uma (re)criação" (HUTCHEON, 2013: 29). Para isso, o adaptador precisa se apropriar do material adaptado e desenvolver um processo de reformulações e readequações, dependendo das suas ideias e da mídia para a qual pretende transpor. Se formos relacionar a duplicidade do termo com o nosso objeto de análise, podemos distinguir que existe um produto (um filme em animação de 21 minutos) e um processo desenvolvido pelo animador Koji Yamamura e pela sua equipe de produção, que buscaram criar um estilo próprio para transpor o universo do conto kafkiano.

Ainda na linha de pensar as adaptações como um fenômeno de rede, de textos que se tocam, se sobrepõem, se apagam superficialmente e se influenciam mutuamente, trazemos a discussão de Roland Barthes (2004) sobre obra. O autor realiza um deslizamento epistemológico que aponta para o surgimento de um novo objeto, a que ele se refere como Texto (BARTHES, 2004). A primeira distinção importante é que a obra possui uma dimensão física, uma existência computável e concreta, enquanto o Texto, por sua vez, se abriga na linguagem, configurandose como um campo metodológico (BARTHES, 2004).

Nesse sentido, é possível detectar a existência de vários textos (com letra minúscula) construídos a partir da obra de Kafka, a começar pela sua extensa fortuna crítica, que comporta múltiplos olhares acerca do mesmo objeto e variadas percepções teóricas. Tudo isso junto e mais outras espécies de trabalhos sobre o tema formam um grande Texto (em maiúsculo), que configuram um conjunto (um campo) de discursos sobre o autor. Aproximando essa ideia do nosso objeto de estudo, podemos pensar que o conto Um médico rural é a obra, e que a adaptação audiovisual é o texto. Dessa forma, enquanto a obra acaba possuindo certa filiação com seu autor, o texto permite ser mais facilmente despedaçado, transformado, atualizado. No caso das adaptações, por exemplo, não há uma obrigatoriedade de serem fiéis à obra. Novas narrativas podem ser criadas a partir disso e outras leituras podem surgir, uma vez que a partir dessa quebra se torna possível juntar os estilhaços e tecer algo novo.

A partir de agora, veremos como a obra literária é transformada e recriada, resultando em um novo texto. Atrelado ao método de análise fílmica de Francis Vanoye e Anne Goliot-Lété (2008), utilizamos os elementos que compõem a estética das animações, trabalhados por Maureen Furniss (2007), para realizar o cruzamento entre a animação e o texto literário. 


\section{Análise da animação e do conto}

Um médico rural (Ein Landarzt) é uma pequena narrativa que dá nome a uma coletânea de contos escrita por Franz Kafka, publicada em 1919 por Kurt Wolff. São quatorze histórias bem breves, dedicadas ao pai do escritor, que conseguem reunir precisamente o já descrito estilo kafkiano. Em meio a uma nevasca, o único médico do distrito recebe um chamado urgente: precisava atender um garoto gravemente doente a dez milhas de distância. O problema é que seu cavalo havia morrido devido ao excesso de esforço da última viagem. Portanto, o médico já não tinha mais como se deslocar até o paciente. Estava a sós com sua criada Rosa, única pessoa que podia ajudá-lo. Ela tentou percorrer a aldeia em busca de outro cavalo, mas não obteve sucesso.

A partir desse ponto, começam a acontecer eventos estranhos, que são recebidos de modo muito natural pelas personagens. O primeiro, por exemplo, é o surgimento inesperado de um cavalariço na pocilga do médico. $O$ homem desconhecido tinha consigo dois cavalos fortes e sadios, o que possibilitaria o deslocamento à casa do enfermo. O médico fica em dúvida quanto à partida, pois o cavalariço deixa evidente a sua pretensão de abusar de Rosa quando ficasse sozinho com ela. Mas o protagonista nem teve tempo de pensar: de repente, a viagem que era para durar horas acontece em segundos, como se o médico fosse teletransportado ao destino. Quando chega lá, mais situações inusitadas acontecem, como as atitudes e gestos incomuns da família do garoto, o aparecimento de um coro formado por crianças e a chegada de visitas aleatórias na casa, só para citar algumas. O desfecho também é bastante kafkiano, marcado pela frustração da personagem principal.

${ }^{1}$ No trabalho de conclusão completo, elegemos oito características dos textos de Kafka de acordo com a reflexão teórica realizada: a inversão, a trivialidade do grotesco,

a deformação como método, a paralisação do tempo e das imagens, a linguagem precisa, o narrador insciente, a adaptação e o caráter gestual das ações. Agrupamos essas oito características em quatro tópicos, colocando-as em duplas a partir de trechos que contemplassem as duas situações de cada subseção.
Para esta etapa ${ }^{1}$, trabalharemos algumas características que discutimos anteriormente acerca da literatura de Kafka: a deformação como método, a paralisação do tempo e das imagens, a linguagem precisa/o narrador insciente e a adaptação. Segundo os estudos de Maureen Furniss (2007), devemos atentar aos elementos que compõem a mise-en-scène: o design da imagem (análise das figuras e fundos), as cores e os movimentos (FURNISS, 2007).

\section{A deformação como método e a paralisação do tempo e das imagens}

Este primeiro item é o conceito criado por Günther Anders (2007) para descrever a operação de deslocamento que Kafka realiza: o escritor trata com naturalidade algo que é convencionado como esquisito. Para ilustrá-la, selecionamos o trecho dos 5'41" até 6'07", que corresponde ao momento do conto em que o médico é transportado quase magicamente até o paciente, cuja casa situava-se a dez milhas de distância. As palmas do cavalariço estimulam a mudança de estado:

Bate palmas; o veículo é arrastado como madeira na correnteza; ainda ouço quando a porta da minha casa estrala e se espatifa ao assalto do cavalariço, depois olhos e ouvidos são tomados por um zunido que penetra uniformemente todos os meus sentidos. Mas por um instante apenas, pois como se diante do portão do pátio se abrisse o pátio do meu doente, já estou lá; os cavalos estão quietos; a neve parou de cair; o luar em volta; os pais do doente saem correndo da casa, a irmã dele atrás; quase me arrancam do carro. (KAFKA, 2010: 15)

Na animação, esse deslocamento dura exatamente dez segundos: é o momento mais veloz do filme, quando curtos flashes aparecem rapidamente para indicar um movimento imediato. O primeiro quadro (Figura 1) é responsável por produzir essa mudança de estado para uma situação mais brusca. Nesse ponto, a figura do cavalariço não é muito nítida, sobretudo o rosto, que parece estar envolto em uma atmosfera de suspense. $\mathrm{O}$ ar de superioridade e empoderamento são ressaltados, uma vez que o desenho da sua forma ocupa quase a totalidade do quadro. 


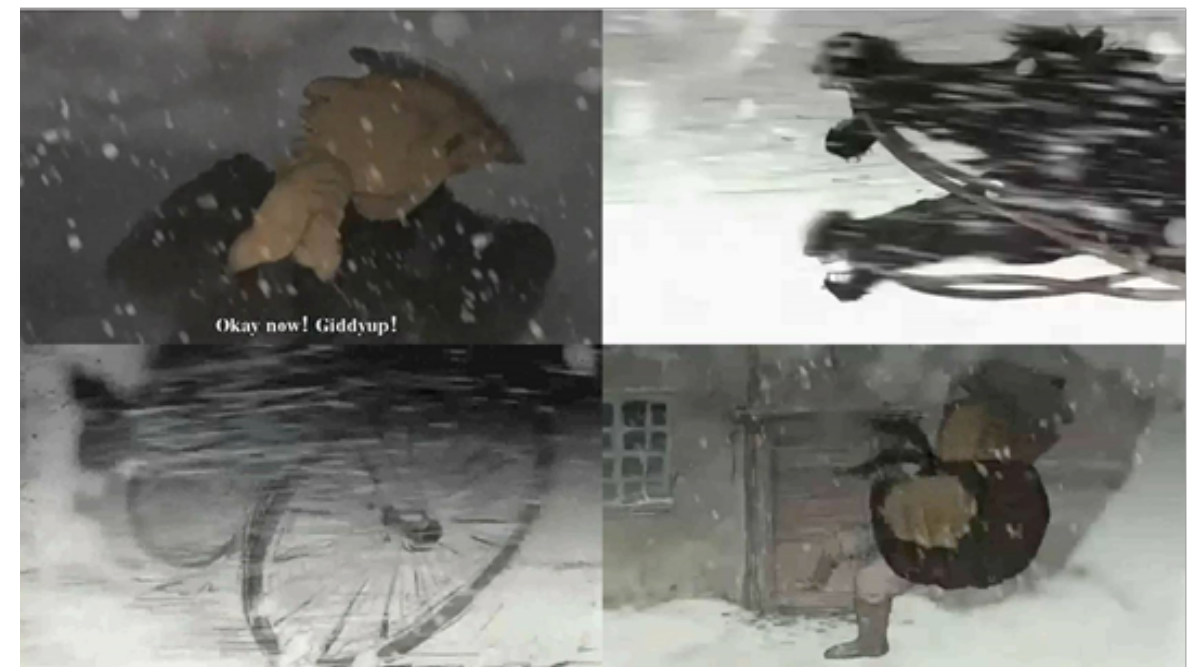

Figura 1: A deformação como método

Fonte: Kafka Inaka Ihsa (2007)

Em seguida, vemos flashes dos cavalos correndo a uma velocidade muito alta; depois, as rodas girando velozmente são destacadas (as linhas em volta da roda potencializam a ideia de movimento); logo após, vem a cena do cavalariço invadindo a casa para abusar da criada Rosa, que já estava completamente sozinha. Nesses rápidos instantes, existe uma sucessão de sons que atuam em conjunto e que colaboram para a sensação de caos e de velocidade absurda: o relinchar dos cavalos, os gritos assustados do médico, o barulho das rodas, o estalar da porta sendo chutada, o zunido descrito pelo protagonista e o som de um dedo deslizando por um piano tecla a tecla, com o intuito de criar uma ideia de que algo foi transformado magicamente.

De acordo com Furniss (2007), é comum que leigos ou iniciantes no campo deem mais atenção aos componentes visuais de um filme, não se dedicando a desvelar a relevância dos aspectos relativos ao som. A pesquisadora lembra, entretanto, que precisa haver uma comunhão entre todos esses elementos, uma vez que "a maioria das pessoas descobrirá que o segredo do sucesso de muitos filmes premiados é o cuidado com que os elementos auditivos - vozes, efeitos sonoros

${ }^{2}$ No original: "Most people will find that the secret to success for many awardwinning films is the care with which aural elements - voices, sound effects and music - have been handled". e música - foram tratados" (FURNISS, 2007: 83, tradução nossa)2. Para contrastar com toda essa rapidez, os planos seguintes são marcados por uma repentina desaceleração (Figura 2).

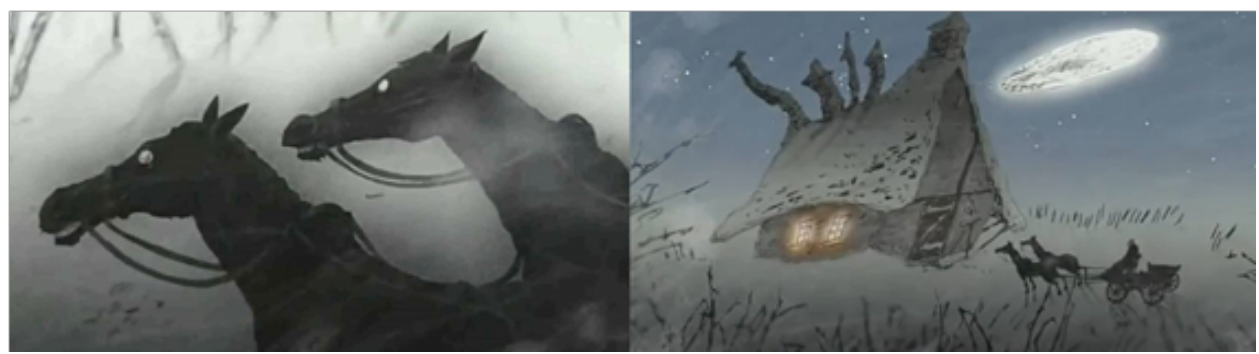

Figura 2: A paralisação do tempo e das imagens

Fonte: Kafka Inaka Isha (2007)

Nesses dois quadros, os elementos do plano ficam completamente estáticos por quatro segundos (a imagem dos cavalos) e por oito segundos (a imagem ao lado), apenas ocorre um movimento de aproximação do quadro, como se fosse um zoom de câmera. Podemos pensar que esses dois momentos indicam visualmente a paralisação do tempo e das imagens, característica kafkiana observada por Anders (2007). Na prosa do autor tcheco, as personagens se envolvem em eternas repetições, sempre voltando ao ponto inicial, de modo que não experimentam um avanço no fluxo de espaço e tempo, o que produz essa sensação de imobilidade. 
Claro, a paralisação a que estamos nos referindo não é algo exatamente literal, é um estado da mente das personagens, que anda em círculos. Mas no caso da animação, uma oportunidade de vermos essa situação mental com clareza é através de um congelamento real da imagem, como salientamos através do exemplo. Essas cenas mais estáticas referem-se ao momento em que o médico finalmente chega à casa do enfermo. A sensação de lentidão prepara o espectador para o que vai ocorrer nos trechos seguintes, ajuda-o a retomar o fôlego depois de tantos quadros velozes, além de garantir um clima de suspense. O efeito proposto por Yamamura é capaz de causar um desconforto no espectador e de fazê-lo refletir sobre o andamento do filme, uma vez que provoca uma ruptura muito forte no ritmo do vídeo ao sair de uma cena muito veloz para o ponto zero de movimento no interior do quadro.

Em todo esse trecho do conto, Kafka provoca a deformação ao descrever de modo bem claro e direto, sem grandes surpresas, o fato esquisito de o médico ter aparecido instantaneamente em um lugar que era realmente muito longe. Não prepara o leitor, apenas narra com normalidade algo bastante incomum. Em uma linha estava na sua casa; na outra, já se encontrava a dez milhas. Por sua vez, Yamamura buscou esse efeito através da mudança brusca de estados (velocidade normal, aceleração absurda e, por fim, estagnação), do uso de flashes rápidos e de uma eficaz comunhão sonora.

No cinema, a alternância de estados é possível através do recurso da edição. Quando uma cena é gravada, nem tudo o que foi captado é utilizado. Além disso, os produtos audiovisuais raramente são filmados respeitando a ordem de sua sequência. Por isso, a montagem configura-se como um procedimento extremamente crucial para costurar uma narrativa e dar sentido a uma infinidade de arquivos soltos. No caso da animação, a situação é parecida, mas em vez de imagens gravadas, temos figuras desenhadas. É possível criar uma justaposição de cenas, alterar a velocidade de cada uma ao alongar a sua duração ou acelerar, mexer na luz e na cor, acrescentar movimentos, inserir elementos na tela, enfim.

\section{Linguagem precisa e narrador insciente}

Outra característica bastante marcante da prosa kafkiana é o modo como a linguagem é utilizada. Sendo bem preciso e protocolar, o autor consegue dizer muito com poucas palavras, apenas aquelas que são exatas e necessárias. Outro fator importante é a existência de um narrador pouco confiável, que parece não ter o pleno domínio da história: é, na verdade, um narrador insciente (CARONE, 2009).

${ }^{3}$ No original: "Ich war in grosse verlengenheit".
Em Um médico rural, o narrador está na primeira pessoa do singular, sendo revelado logo na frase que abre o conto: "Eu estava em um grande aperto"3 (KAFKA, 1952: 106, grifo nosso). Quem assume esse pronome (eu) é o próprio médico, que se configura como um narrador que transita por pelo menos três camadas. A primeira delas se constitui de ações que ele vai contando e numerando; a segunda descreve a relação dele com as outras personagens e faz a mediação entre os diálogos; a terceira camada, por sua vez, representa as conversas internas que o narrador tinha consigo mesmo, ou seja, as suas dúvidas, lamentações e reflexões, além de conter as situações que só o médico imaginava.

Depois que chega à casa do paciente e, no primeiro momento, constata que ele está saudável, o protagonista passa a travar um diálogo interno bastante intenso. Começa a refletir sobre os limites de sua profissão, lembrando que, embora seja médico e tenha a incumbência de cuidar dos enfermos, nem sempre será possível salvar a vida de todo mundo: 
aos pobres. Tenho ainda de cuidar de Rosa, além disso o jovem pode estar com a razão e também eu quero morrer. $O$ que estou fazendo aqui neste inverno interminável? (KAFKA, 2010: 17

No filme, esse trecho situa-se entre 9'04" e 10'04". Para dar conta da complexidade narrativa, caracterizada tanto pela escrita calculista quanto pelo narrador em camadas, o animador utiliza um recurso interessante: a criação de duas figuras em preto (primeiro quadro da Figura 3), que simbolizam as sombras do médico. Elas representam a terceira camada, aparecendo nos diálogos que o narrador trava consigo mesmo. Além de as conversas internas serem visualmente mostradas através desses desenhos pretos, o animador escolheu fazer a gravação de voz com outros dois atores.

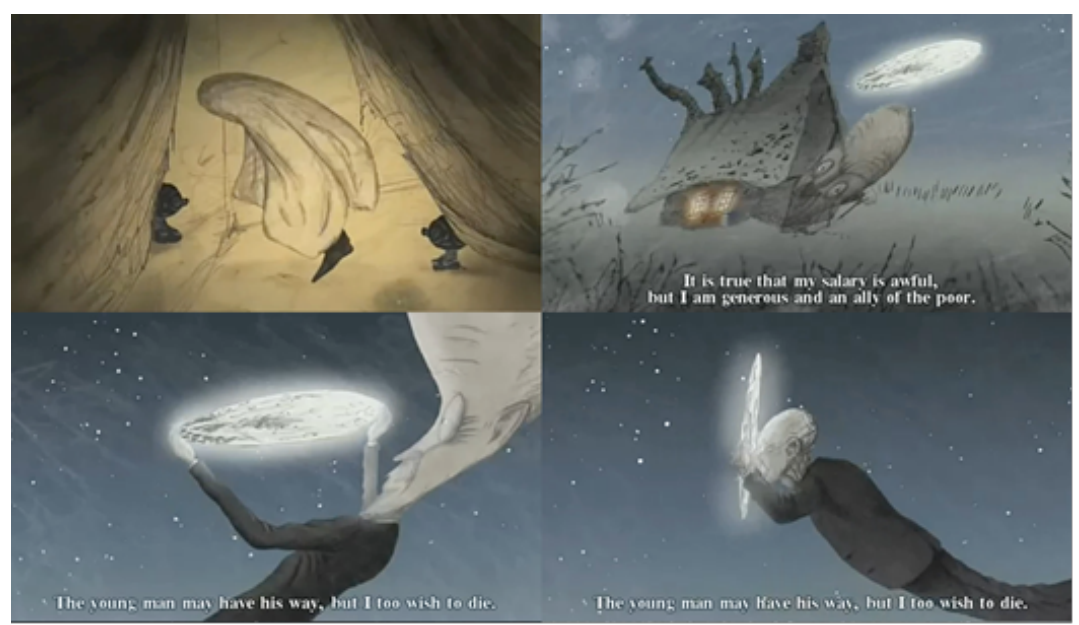

Figura 3: As vozes narrativas

Fonte: Kafka Inaka Isha (2007)

Nas animações, a interpretação de voz não é um fator importante apenas no sentido de ser um fio condutor para a narrativa. Ela também afeta completamente a caracterização e a personalidade das personagens (FURNISS, 2007), sendo um dos componentes principais para dar vida às figuras. Ademais, "interpretar vozes para animação é um trabalho especializado que difere substancialmente de outras ocupações vocais, como a dublagem de filmes estrangeiros ou o fornecimento de

${ }^{4}$ No original: "Performing voices for animation is a specialised job that differs substantially from other voicetalent occupations, such as dubbing foreign films or providing voice-overs for commercials or instructional media. To play the role of an animated character, voice artists generally must alter their normal manner of speaking substantially in terms of both sound (adopting unusual speaking voices) and volume (yelling and crying out is relatively common)". narrações para comerciais ou mídia instrucional" (FURNISS, 2007: 85, tradução nossa $)^{4}$, uma vez que é preciso dar riqueza e significado à personagem sem que apareçam o corpo e o rosto do ator, sendo essencial, muitas vezes, mudar o tom normal de fala. Dessa forma, o médico aparece tendo a sua própria voz (interpretada por Sensaku Shigeyama) e mais outras duas, que surgem com as sombras (interpretadas por Shigeru Shigeyama e Doji Shigeyama). Por ser uma fala japonesa, as dublagens são capazes de causar um estranhamento ainda maior no espectador ocidental, pouco acostumado com o idioma.

Para conseguir transpor algo mais abstrato para uma mídia que envolve a imagem e o som, Yamamura precisou criar algo que não estava no texto. Enquanto a palavra vai dando conta de transmitir os pensamentos do médico no conto, a animação precisava ter uma imagem que se relacionasse com as reflexões. Por isso, o animador interrompe a sequência de cenas no ambiente da casa do doente e, momentaneamente, transporta o espectador para outro cenário (a partir do segundo quadro da Figura 3).

Furniss (2007) defende que é importante dar atenção às cores, pois possuem funções e são capazes de gerar efeitos no espectador. As percepções não são absolutas, podendo variar de acordo com a fisiologia de cada observador e com as diferenças culturais, pois as simbologias são calcadas em convenções. No primeiro quadro da Figura 3, vemos a predominância do amarelo, que sugere 
uma ideia de enfermidade, e do preto, mais acentuado nas bordas do quadro, que remete a uma atmosfera sombria.

A partir do segundo quadro da Figura 3, somos levados para fora da casa e vemos a cabeça do médico saindo pela porta. No cinema, o modo de uma figura se movimentar é capaz de criar efeitos importantes para o sentido que o espectador vai elaborar (FURNISS, 2007). Por isso, o modo lento e avulso como os seus movimentos são executados trazem uma sensação de que o protagonista não estava agindo por vontade própria, parecia mais uma marionete sendo conduzida sem ter nenhum controle do seu destino. Aqui fica evidente que as personagens experimentam uma falta de liberdade diante de sua própria vida.

No terceiro e quarto quadros, observamos uma predominância de cores escuras no cenário, sobretudo tons de preto e azul. Como parte da estética do filme todo, a deformação gráfica da personagem (que muda sua forma em poucos segundos) se faz presente e ajuda a acentuar a atmosfera onírica. Desejando a sua própria morte, o médico toca na lua, e ela logo se transforma em uma espécie de forca, que realiza movimentos pendulares para indicar uma degola. Sendo esse o ápice da tensão e da insanidade da cena escolhida, a trilha sonora se intensifica tanto a ponto de invadir a fala da personagem, rompendo com as hierarquias de som. Furniss (2007) explica que a situação mais comum em filmes é que os diálogos e as narrações de voz sejam mais altos do que a música e os efeitos sonoros. A autora ainda comenta, entretanto, que é possível alterar essa ordem de importância e produzir rupturas (FURNISS, 2007). É exatamente isso que ocorre entre 9'48" e 9'52", momento em que o violino emite sons estridentes e perturbadores, que acabam se sobrepondo à voz do médico.

Ao contrário do texto, essa cena do filme não é tão curta, pois ela precisa respeitar o tempo da imagem, da trilha sonora, do movimento lento das figuras e da dublagem japonesa, que parece ser mais arrastada do que uma fala ocidental. É uma temporalidade bem própria do audiovisual, característica que nos faz entender o motivo de um conto tão breve ter uma duração de 21 minutos no formato fílmico.

\section{A adaptação}

Considerando a estrutura narrativa, já havíamos pontuado que Kafka opera a partir da inversão em relação ao fantástico tradicional (TODOROV, 1975). Se as suas histórias já começam com o acontecimento estranho logo de súbito, o leitor não experimenta a sensação de hesitação, cujo objetivo era preparar o receptor para o ápice do sobrenatural. No seu lugar, surge a adaptação, que é um "procedimento simétrico e inverso" ao da hesitação (TODOROV, 1975: 179).

O trecho escolhido para ilustrar esse momento situa-se entre os tempos $13^{\prime} 11^{\prime \prime}$ e $14^{\prime} 02^{\prime \prime}$ da animação. Nesse ponto, o médico já havia percebido que o garoto estava de fato doente e pensava que não teria mais como salvá-lo. Diante disso, começa um novo diálogo interno, refletindo sobre os abusos que sofre na profissão. Depois desses pensamentos, algumas situações esquisitas começam a acontecer. Ao invés de as personagens se mostrarem assustadas diante do estranho, elas reagem de modo bastante natural. Com isso, a ideia é que o leitor vá sendo adaptado ao insólito, vá aceitando o caráter inusitado dos acontecimentos até chegar a um ponto de naturalização e de resignação total:

Assim são as pessoas na minha região. Sempre exigindo o impossível do médico. Perderam a antiga fé; o pároco fica sentado em casa desfiando uma a uma as vestes litúrgicas; mas o médico deve dar conta de tudo com sua delicada mão de cirurgião. Bem, como quiserem: não me ofereci; se abusam de mim visando a objetivos sagrados deixo que também isso aconteça comigo; o que mais desejo de melhor, eu, velho médico rural a quem roubaram a criada? E eles vêm, a família e os anciãos da aldeia, e me despem; um coro de escola, professor à 
frente, está diante da casa e canta uma melodia extremamente simples com a letra: Dispam-no e ele curará! E se não curar, matem-no! É apenas um médico, apenas um médico! - Estou então sem roupa e, os dedos na barba, a cabeça inclinada, olho com tranquilidade as pessoas. - Completamente composto e superior a todos, permaneço assim embora isso não me ajude em nada, pois elas agora me pegam pela cabeça e pelos pés e me carregam para a cama. Colocam-me junto à parede, do lado da ferida. (KAFKA, 2010: 19)

O surgimento completamente aleatório de anciãos da aldeia, as pessoas desnudando o médico, o aparecimento de um coral infantil conduzido por um maestro e os figurantes carregando o protagonista até a cama do enfermo são exemplos de situações descabidas que ocorrem nesse trecho. $O$ narradorpersonagem vai conduzindo essas ações tranquilamente, sem mostrar nenhum esboço de surpresa. É muito frequente o uso do ponto e vírgula para separar as ações, passando de uma à outra rapidamente, tratando tudo de forma muito comum, como se fosse algo bastante corriqueiro.

Agora, veremos que estratégias Yamamura utilizou para mostrar o que a característica da adaptação sugere: o aceitar, com naturalidade, os acontecimentos bizarros e o agir despreocupado, como se tudo estivesse dentro dos conformes. Analisando as cenas, notamos que a grande saída encontrada pelo animador foi de trabalhar o modo como se movimentam as personagens. Esse fator é tão relevante que é o ponto definidor da própria perspectiva de animação do importante artista escocês Norman McLaren (1995 apud FURNISS, 2007: 5, tradução nossa), que defende que "a animação não é a arte dos desenhos que se movem, mas a arte dos movimentos que são desenhados; [...] a animação é, portanto, a arte de manipular

${ }^{5}$ No original: "Animation is not the art of drawings that move but the art of movements that are drawn; [...] Animation is therefore the art of manipulating the invisible interstices that lie between the frames". os interstícios invisíveis que se encontram entre os quadros"

No primeiro quadro (Figura 4), por exemplo, temos o momento em que os anciãos entram na casa: são passos constantes, como se estivessem marchando conjuntamente, de forma que inclusive o som dos seus sapatos no piso sugere a ideia de "marchar". Esse modo de andar, obstinado, preciso e ritmado, indica que essas pessoas sabem muito bem o que vieram fazer ali na casa. E elas vão avançando, caminhando pelo espaço, determinadas a executar alguma ação, de modo que essa parte termina com as pernas dos anciãos invadindo o quadro: é um passo tão obstinado que devora o plano. Além disso, a decisão de enquadrar apenas os pés é uma forma de criar um mistério acerca do que está por vir e de salientar a importância do movimento de andar.

A ideia de um caminhar que se aproxima de um marchar também se repete no último quadro (Figura 4), quando o médico é carregado pelo grupo de anciãos. A composição do cenário é escura em todos os planos, de modo que apenas um foco de luz aparece em destaque em cada cena. Dessa forma, existe uma predominância de sombras e de efeitos voltados para o preto com o intuito de criar uma atmosfera pesada. Essa ambientação obscura e com uma iluminação amarelada remete a uma espécie de velório, como se os vizinhos e a família estivessem organizando um ritual para se despedir do garoto enfermo. Isso nos leva a pensar na fatalidade do destino das personagens kafkianas, sempre impossibilitadas de ter qualquer redenção.

No penúltimo quadro (Figura 4), conseguimos enxergar um pouco melhor o rosto dos anciãos, mas também não é uma visão muito esclarecedora: vemos um movimento horizontal de câmera, uma panorâmica, que vai passando e mostrando os rostos. A questão é que todos usam chapéu e acabam, assim, tendo quase toda a sua face coberta por ele. Com a cabeça inclinada para baixo e o olhar voltado para o chão, só é possível ver claramente as bocas e os bigodes. A postura deles, embora tenha o caráter já mencionado da obstinação, traz uma sensação de que têm consciência das suas ações, mas as realizam por ordem de terceiros, parecendo que são verdadeiras marionetes cumprindo tarefas. 


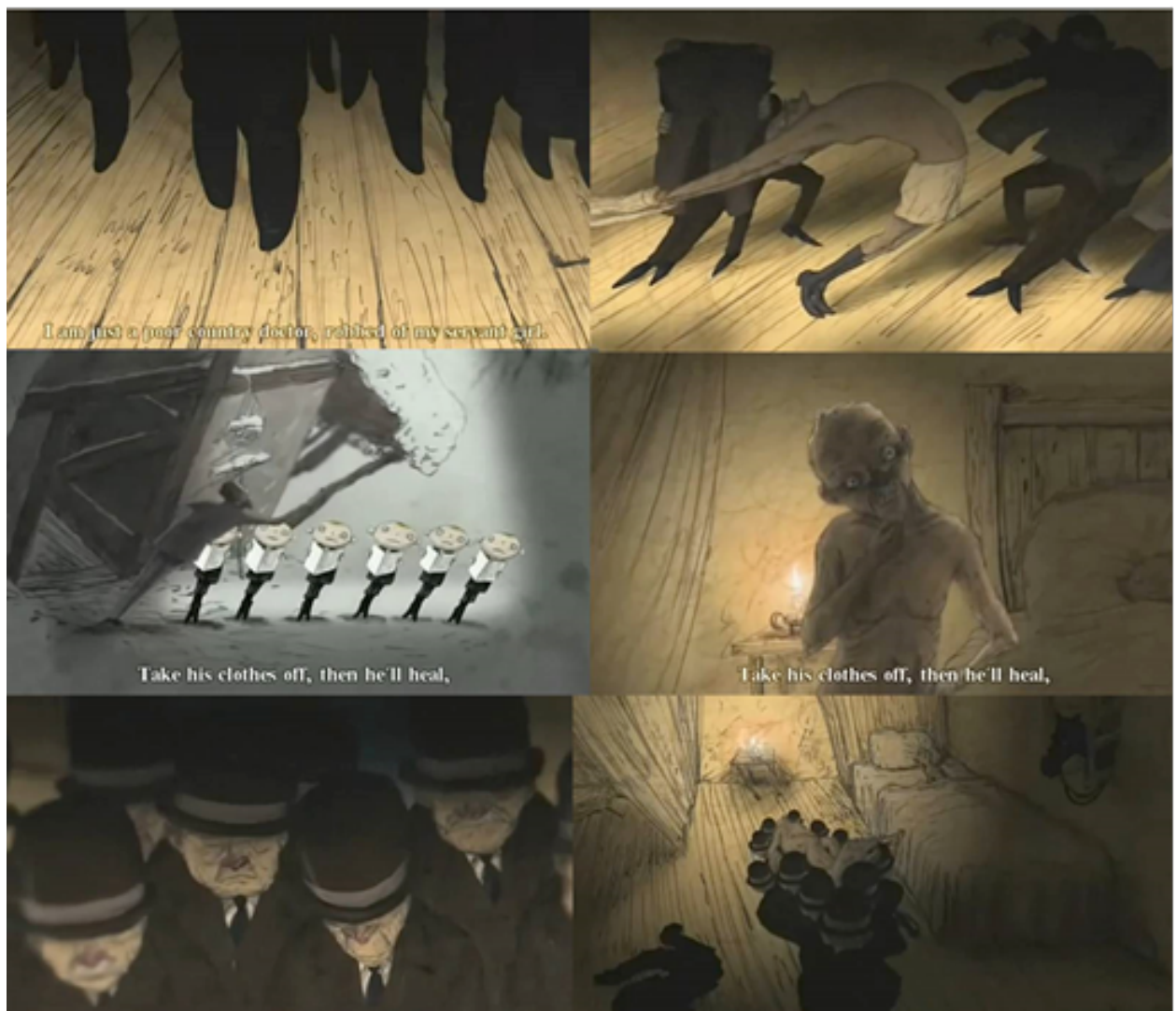

Figura 4: A adaptação no lugar da hesitação

Fonte: Kafka Inaka Isha (2007)

No segundo quadro (Figura 4), vemos a parte em que as pessoas tiram as vestes do médico. Geralmente, para dar uma sensação de estranhamento, opta-se por movimentos bruscos, que causam desconforto. Nesse exemplo, entretanto, observamos movimentos lentos, justamente para ajudar a sugerir a ideia de adaptação, de familiaridade com o esquisito. Assim, o médico se curva todo, e, lentamente, puxam as roupas do seu corpo. A lentidão, nesse caso, indica uma naturalidade: não existe motivo para a pressa se estamos familiarizados com os eventos. A atmosfera continua bastante misteriosa e sombria, principalmente devido à composição das cores, muito carregadas pelas manchas escuras ao redor da imagem. Além disso, as linhas do desenho (tanto as do chão quanto as que contornam as personagens) são inclinadas, o que contribui para uma aparência alongada e arrastada.

No quadro do coral (Figura 4), as crianças também agem normalmente, como se estivessem em mais um dia comum de ensaios. Todas se mostram muito atentas e focadas em sua atividade, inclusive o maestro, cujos pés parecem estar colados ao chão, realizando movimentos de inclinação do corpo e gestos com as mãos. Quando começam a cantar, um foco de luz dirige-se às crianças, sugerindo que se trata de um verdadeiro espetáculo. É esse agir obstinado e carregado de seriedade que indica a ideia de adaptação, pois mesmo sendo muito aleatório o fato de um coral surgir em meio à nevasca e começar a cantar uma canção intimidando o médico, eles desempenham seu trabalho normalmente.

\section{Considerações finais}

Discutir adaptações significa aceitar que as mudanças são inerentes ao processo, pois adaptar exige, antes de tudo, que haja uma reformatação. Defendemos, em virtude disso, que é crucial nos afastarmos de uma hierarquização entre as mídias cuja finalidade seja de eleger qual produção é a melhor. Fora isso, confirmamos que podemos pensar a animação do conto a partir da ideia de palimpsesto 
(HUTCHEON, 2013), considerando que ela é um objeto estético por si só, mas que possui vínculos importantes com a obra de partida.

A multiplicidade de camadas que caracteriza as adaptações também reforça a concepção de Texto (BARTHES, 2004). Nesse caso, Koji Yamamura dirigiu-se a um jogo de criação de algo novo, podendo ter tido contato com outros textos sobre Kafka (críticas, ensaios e outras adaptações, por exemplo), e, assim, fez o seu pequeno texto (a animação) e contribuiu para tecer um pouco mais o grande Texto (os discursos) que existe ao redor do autor tcheco.

$\mathrm{Na}$ análise, percebemos que uma das principais estratégias utilizadas pelo artista foi a deformação gráfica dos desenhos. Em poucos segundos, as personagens sofrem várias alterações em sua forma, tendo seus contornos bastante distorcidos de acordo com o decorrer de cada ação. Esse recurso ajuda, sobretudo, a passar uma característica muito recorrente nos textos kafkianos: a sensação de estranhamento. Somado a isso, os sons perturbadores do piano e do violino promovem uma ambientação tensa e pesada, colaborando para constituir uma atmosfera opressora e bastante assustadora, próxima de um pesadelo.

Diante de uma obra tão aberta como a de Kafka, o animador japonês precisou fazer a sua leitura e escolher elementos e referências para criar o seu filme, isto é, recriar o conto do escritor tcheco em outra linguagem. Considerando essas escolhas estéticas, observamos que Yamamura se aproximou, de algum modo, do expressionismo alemão ao buscar a expressão do efeito emocional a partir da distorção visual. Nessa corrente do cinema, é comum utilizar alguns cenários calcados em perspectivas irreais, propor um uso exagerado da luz e da sombra e demarcar a importância da atuação e dos movimentos das figuras. Dessa forma, é criada uma ambientação bastante onírica e distante do real, que dirige a nossa atenção à psicologia das personagens. Assim, o trabalho de Yamamura se aproxima muito desse conceito expressionista do cinema, iniciado entre as duas grandes guerras, durante a República de Weimar (1918-1933).

Nesse ponto, cabe uma diferenciação interessante em relação ao literário: com essas estratégias, a animação é capaz de conduzir o espectador a uma espécie de terror, enquanto no mundo das palavras esse traço não é explícito. Através do desenho, que é algo visualmente dado, o filme entrega sensações e situações que estão apenas contidas na obra textual, mas que não estão evidentes. Assim, a partir do exagero, da deformação e dos sons, a animação mostra-se capaz de expandir sugestões que o literário não entrega de antemão. O leitor, por outro lado, pode inventar interpretações mais livremente, criar o cenário da história em sua imaginação, romper esse contrato quando ele bem entender e criar outro universo, diferente do mundo já desenhado na animação, com o qual o espectador terá de lidar até o final.

Outra escolha responsável pela singularidade da recriação foi o convite ao ator Sensaku Shigeyama para dublar a voz do médico. Ele faz parte do teatro de kyogan, que é uma forma cômica de teatro japonês tradicional, surgida há mais de 800 anos. Uma de suas características peculiares é justamente a existência de personagens periféricos à sombra do ator principal, que performam músicas e narrações sobre a trama. Inspirado nessa ideia, Yamamura construiu a já mencionada complexidade narrativa do conto e do protagonista através da gravação de voz com mais dois atores (Shigeru Shigeyama e Doji Shigeyama), que interpretavam o som das figuras pretas, responsáveis por designar os diálogos internos do médico.

Sem grandes problemas, é fácil notar que a narrativa kafkiana é predominantemente ocupada por uma atmosfera pesada e tensa, mas que abriga consigo uma pitada de deboche e humor. O próprio modo como conduz a narrativa, tratando como trivial algo absurdo, já é capaz de construir um componente risível. Ou, então, o fato de uma personagem fracassar por motivos 
tolos acaba constituindo uma estética debochada. Yamamura, ao seu modo, extrapola o caráter tenso, chega ao terror e mantém um pouco do ar cômico a partir das interpretações vocais.

Fora esses recursos, o artista japonês depositou bastante valor na maneira de andar das personagens e no modo como realizavam os movimentos. Para estabelecer o típico estranhamento kafkiano, trabalhou com mudanças bruscas de estados, contrastando rápidos flashes com cenas praticamente imóveis. No âmbito fotográfico, optou primordialmente por dois cenários: a nevasca, onde o uso de cores mais frias remetia a um estado mais opressivo, e o cenário da casa do paciente, colorido por tons amarelados. Nesse caso, a cor não traz uma ideia de calor e de vida, mas sim de doença. A iluminação também colaborou para uma atmosfera opressora: a maior parte do filme contou com um cenário tomado pela escuridão, onde só se enxergava apenas um foco de luz.

Se Kafka é capaz de exercer uma violência pela palavra e de produzir afetos e desloucamentos que nos destituem da nossa própria condição de leitor habitante do mundo, a animação de Yamamura também não passa incólume aos olhos do espectador: de modos diferentes, as duas produções conseguem articular a atmosfera fantástica e trabalhar com complexas questões subjetivas.

\section{Referências}

ADORNO, T. Anotações sobre Kafka. In: ADORNO, T. Prismas: crítica cultural e sociedade. Tradução de A. Wernet, J. de Almeida. São Paulo: Ática, 1998. p. 239-270.

ANDERS, G. Kafka: pró e contra. São Paulo: Cosac Naify, 2007.

BACKES, M. Posfácio. In: KAFKA, F. Blumfeld: um solteirão de mais idade e outras histórias. Tradução de Marcelo Backes. São Paulo: Civilização Brasileira, 2018.

BARTHES, R. Da obra ao texto. In: O rumor da língua. 2. ed. Tradução de Mario Laranjeira. São Paulo: Martins Fontes, 2004. p. 65-75.

BENJAMIN, W. Kafka. Tradução de Ernesto Sampaio. Lisboa: Hiena, 1994.

CARONE, M. Lição de Kafka. São Paulo: Companhia das Letras, 2009.

FURNISS, M. Art in motion: animation aesthetics. London: John Libbey, 2007.

HUTCHEON, L. Uma teoria da adaptação. Tradução de André Cechinel. Florianópolis: Ed. UFSC, 2013.

KAFKA, F. Ein Landarzt. In: KAFKA, F. Das Urteil. Hamburg: Fischer Bücherei KG, 1952.

KAFKA, F. Um médico rural. Tradução de Modesto Carone. São Paulo: Companhia das Letras, 2010.

KAFKA Inaka Isha. A country doctor. Direção: Koji Yamamura. Roteiro, edição, câmera: Koji Yamamura. Produção: Mariko Seto e Fumi Teranishi. Música: Hitomi Shimizu. Japão: [s. n.], 2007. Vista/DOLBY Digital (21min), son., color., 35 mm, 1: 1,85 (16: 9).

TODOROV, T. Introdução à literatura fantástica. 2. ed. Tradução de Maria Clara Correa Castello. São Paulo: Perspectiva, 1975. (Coleção Debates 98).

VANOYE, F.; GOLIOT-LÉTÉ, A. Ensaio sobre a análise filmica. Tradução de Marina Appenzeller. Campinas: Papirus, 2008. 